\title{
The Antibacterial Action of Various Silver Nanoparticles Used for the Stone Treatment ${ }^{+}$
}

\author{
Liliana Marinescu 1, Angela Spoiala 1, Ecaterina Andronescu 1,*, Anton Ficai 1, Denisa Ficai 1, \\ Alina-Maria Holban ${ }^{2}$ and Ovidiu Oprea ${ }^{1}$ \\ 1 Faculty of Applied Chemistry and Materials Science, Polytechnica University of Bucharest, Gh Polizu 1-7, \\ 011061 Bucharest, Romania; liliana10marinescu@gmail.com (L.M.); angela.8317@gmail.com (A.S.); \\ anton.ficai@upb.ro (A.F.); denisa.ficai@upb.ro (D.F.); ovidiu73@yahoo.com (O.O.) \\ 2 Biology Faculty, University of Bucharest, Intrarea Portocalelor nr 3, 060101 Bucharest, Romania; \\ alina_m_h@yahoo.com \\ * Correspondence: ecaterina.andronescu@upb.ro \\ † Presented at the 16th International Symposium "Priorities of Chemistry for a Sustainable Development" \\ PRIOCHEM, Bucharest, Romania, 28-30 October 2020.
}

Published: 15 November 2020

Keywords: preservation; wooden artifacts; commercial products; characterization

The antibacterial effect of silver nanoparticles is known from the ancient world. Based on their high antimicrobial effect, silver nanoparticles can be used in stone treatment together with siloxanes components as the coupling agent. The application of certain silver nanoparticles on the stone treatment could be used as the protection of stone monuments, claddings, and heritages. The antibacterial effect of silver nanoparticles consists of the protection of various surfaces against the formation of biofilms.

The present work aims to follow the impregnation of various types of stone, usually used in the construction as décor elements, travertine, limestone, marble, with different products as siloxanes and silver nanoparticles solutions to protect their surface against aggressive climatic factors and microorganisms. The silver nanoparticles obtained by different methods were chosen, based on their antibacterial effect, to treated various substrate. It is known the antibacterial effect of the silver nanoparticle acting against on the various microorganism strains. The application of silver nanoparticles as the protective film or the impregnation of stone substrates shown an efficiency against the microorganism formation acting not only on the surface of the treated substrate also inside of their structure [1-3].

The silver nanoparticles were obtained by chemical methods at room temperature or solvothermal method using silver nitrate and various reducing and stabilizer agents as sodium borohydride, sodium citrate, polyethylene glycol, polyvinylpyrrolidone. The selected stones' surfaces were treated with siloxanes, as the coupling agent with thiol groups containing various silver nanoparticles synthetized by various routes [4-6]. The impregnated stones were tested by FTIR, SEM EDAX, and microbiological tests. All tests were done confirmed the presence of silver nanoparticles both on the stone treated surface also inside of the stone structure. The biological test confirmed the presence and activity of silver nanoparticles against the microorganisms. Figure 1 IR spectra indicated the impregnation of the limestone confirmed by the SEM EDAX test. 

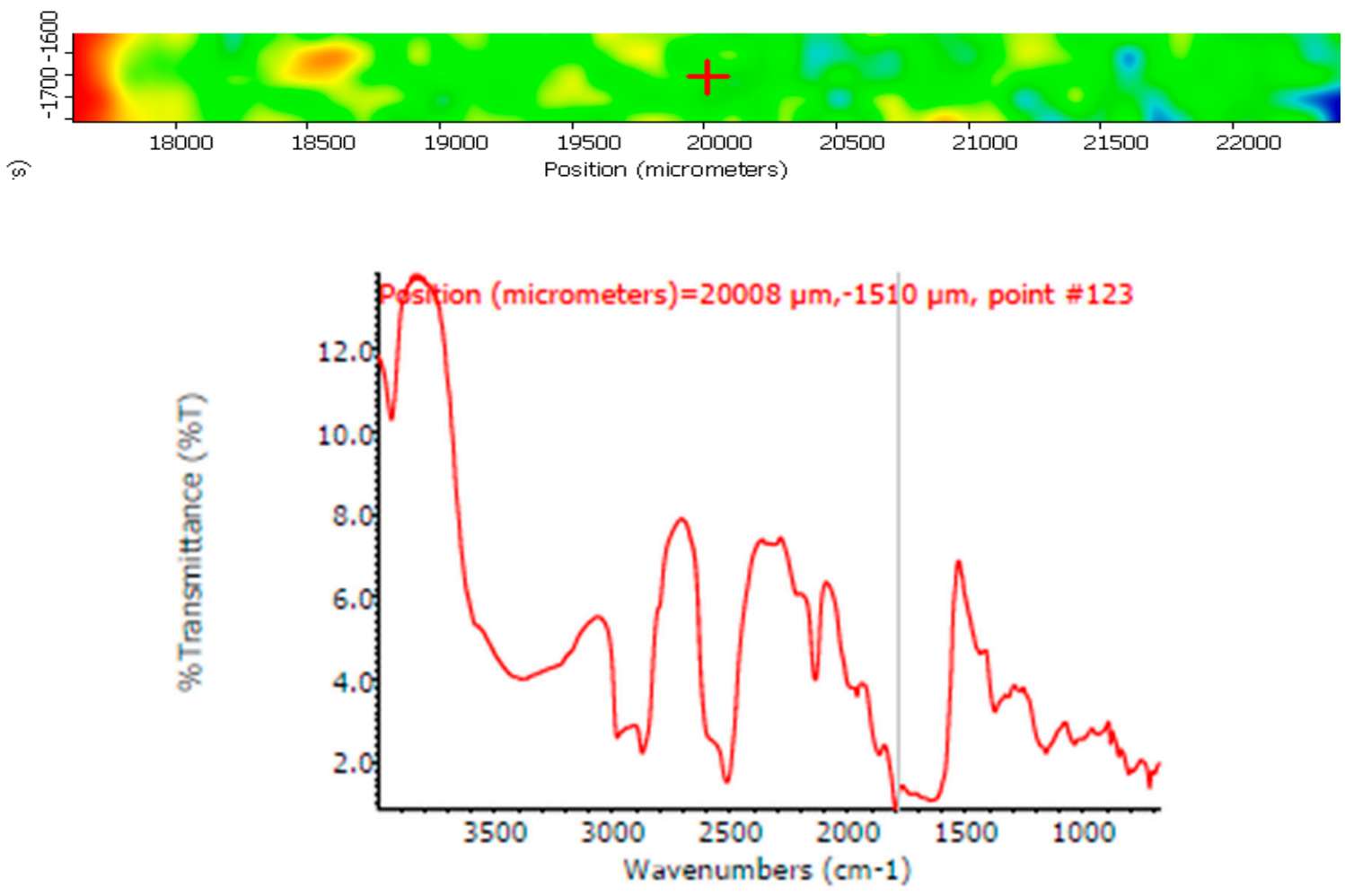

Figure 1. Limestone impregnated with the mixing of the COAT O SIL product and alcohol.

The treatment of the stone surface with silver nanoparticles using various types of siloxanes could lead to the high antimicrobial efficiency of the surface with a protective role against the formation of biofilms.

\section{References}

1. Kakakhel, M.A.; Wu, F.; Gu, J.D.; Feng, H.; Shah, K.; Wang, W. Controlling biodeterioration of cultural heritage objects with biocides: A review. Int. Biodeterior. Biodegrad. 2019, 143, 104721.

2. Becerra, J.; Zaderenko, A.P.; Gomez-Moron, M.A.; Ortiz, P. Nanoparticles Applied to Stone Buildings. Int. J. Archit. Herit. 2019, doi:10.1080/15583058.2019.1672828.

3. Toreno, G.; Isola, D.; Meloni, P.; Carcangiu, G.; Selbmann, L.; Onofri, S.; Caneva, G.; Zucconi, L. Biological colonization on stone monuments: A new low impact cleaning method. J. Cult. Herit. 2018, 30, 100-109.

4. Nowicka-Krawczyk, P.; Zelazna-Wieczorek, J.; Kozlecki, T. Silver nanoparticles as a control agent against facades coated by aerial algae-A model study of Apatococcus lobatus (green algae). PLoS ONE 2017, 12, e0183276.

5. Paladini, F.; Pollini, M. Antimicrobial Silver Nanoparticles for Wound Healing Application: Progress and Future Trends. Materials (Basel) 2019, 12, 2540.

6. Pinna, D. Coping with Biological Growth on Stone Heritage Objects, 1st ed.; Apple Academic Press: New York, NY, USA, 2017.

Publisher's Note: MDPI stays neutral with regard to jurisdictional claims in published maps and institutional affiliations.

(C) 2020 by the authors. Licensee MDPI, Basel, Switzerland. This article is an open access article distributed under the terms and conditions of the Creative Commons Attribution (CC BY) license (http://creativecommons.org/licenses/by/4.0/). 